\title{
EDITORIAL
}

\section{Conciencia, Cultura y Humanismo en la Historia}

\author{
Francisco Alberto Pérez Piñón
}

Director

omo parte de la presentación de los artículos científicos que se difunden en este número, iniciamos con la discusión que en la actualidad existe en el campo de la historia, de antemano, sin considerarla aislada de las distintas disciplinas de las ciencias sociales y las humanidades. En el sigo XXI las barreras disciplinarias tienden a diluirse, lo que permite -en el caso de la historia- pensar en la interdisciplinariedad en los abordajes de los objetos de estudio, con el fin de profundizar en ellos con miradas trascendentales (Mora, 2003) y así superar el encave de los acontecimientos históricos desde las empíreas y dar paso a las interpretaciones con sentido, en beneficio de la construcción de la sociedad a la que aspiramos vivir.

El sustento para esta editorial en el historiador de origen alemán Jörn Rüsen ${ }^{\mathrm{I}}$, nos permite conocer enfoques desde otras latitudes, y no solamente desde la visión de la línea de investigación trazada por los franceses, desde la famosa y paradigmática Escuela de los Annales, hasta su desarrollo más cercano de la historia cultural o los estudios de los lugares de la memoria de Pierre Nora, de quienes se ha seguido su desarrollo en esta disciplina. Ahora, en este plexo tomamos un atisbo de lo que los alemanes están realizando a través del mencionado personaje y a quienes regularmente dejamos de lado precisamente, no por sus bondades, sino por el imaginario social que ha quedado después de las dos conflagraciones bélicas y el tema tan abominable del holocausto. Rüsen, es un personaje de quien pocas obras y escritos han sido traducidos a nuestro idioma, 
pero aún por lo incipiente de su lectura, convence la forma en cómo están trabajando la disciplina de la historia desde las aulas y el peso que le dan a este campo en la formación de las nuevas generaciones. El primer concepto, el de conciencia histórica, nos remite a que:

Es una teoría de creación de sentido histórico, en la que interviene la memoria histórica como componente principal de la conciencia histórica, movilizándose ambas en la conformación de la cultura histórica. Esta se define por aquel conjunto de funciones a través de las cuales un individuo y/o una sociedad crea una relación activa con su pasado mediante una experiencia temporal, que debe ser percibida e interpretada antes de volverse elemento de orientación y motivación en la vida humana (Cataño, 20II, p. 223)

Rescatamos los dos elementos que con esta cita nos menciona Cataño: el sentido y la memoria histórica; el primero, lo podemos enunciar como la orientación y las motivaciones que se tienen en relación a la sociedad y a la dirección hacia donde se desea su desarrollo, y las aspiraciones de conservación y cambios culturales. La memoria se concibe como ese dispositivo capaz de recordar los acontecimientos pasados, teniendo siempre al presente como parte de esos acontecimientos. La afectación por el pasado permite la toma de conciencia, a la vez que constituye y reconstruye la cultura. La conciencia histórica y su expresión social, desde la visión de Rüsen, es posible conocerla a través de las actividades narrativas. Con estas ideas, discutibles por supuesto, se están realizando trabajos en educación en distintos países, en donde se trata de conocer la conciencia histórica de los estudiantes en distintos niveles educativos, a través de las narrativas.

En relación al concepto de cultura histórica, podemos enunciar que es la fuerza con la cual los acontecimientos pasados tienen la presencia y conformación simbólica en el presente. Poder conocer e interpretar los pasados remotos o cercanos en el presente y son 
dispositivos que se manifiestan a la hora de realizar las valoraciones sociales y otorgarles sentido, por lo que se puede definir como:

[...] un concepto heurístico e interpretativo para comprender e investigar cómo se crean, se difunden y se transforman unas determinadas imágenes del pasado relativamente coherentes y socialmente operativas, en las que se objetiva y articula la conciencia histórica de una comunidad humana. Esa comunidad humana, ese "sujeto colectivo", puede acotarse, aunque no como un compartimento estanco, según múltiples criterios: nacionalidad, lengua, religión, género, clase, generación que comparte experiencias formativas o civilización que se basa en un legado simbólico y material común (Sánchez, 2009, p. I).

La cultura histórica es constitutiva de los legados materiales y simbólicos con los cuales se estructuran las maneras y formas de actuar en la vida práctica. Los fines de este conglomerado cultural, son valorar las acciones históricas pasadas, otorgarles sentido y proyectarlas al futuro. Por lo tanto, tener cultura histórica es estar consciente de que el presente es, debido a la presencia del pasado, en donde no existen creaciones nihilistas, sino construcciones, sin olvidar que la cultura social es dinámica y siempre está en constante reformulación.

El tercer concepto -que hemos dejado para el final- es el de humanismo, que se entiende como la construcción social que se manifiesta gracias a la cultura y a la conciencia histórica. En este aspecto, Rüsen se basa en la filosofía Kantiana para la elaboración de la propuesta y aquí manifiesta la parte romántica -a nuestro juicio- en las fases de la paz perpetua (Santiago, 2004), en donde la federación de estados -sociedad- basados en las acciones prácticas, deben tender a apelar a las concepciones de racionalidad e inteligencia, buscar evitar la guerra y plantearse el bien y la paz de manera permanente. Con la cita siguiente dejamos testimonio de que el humanismo: 
[...] proporciona un significado esencial a este parecer instalado en el interior de la estructura de sentido y de los procesos de construcción de sentido de las vidas individual y social. También podemos decir que el humanismo representa algo así como una fundamentación cultural de la Humanität, o que el humanismo representa una suerte de meta-texto grabado en el tejido cultural que conecta los diversos sentidos culturales con un sentido de la Humanität que todas las culturas comparten (Kozlarek, 20I87, p. 37).

No es complicado de entender este humanismo desde la postura de Rüsen, que propone la búsqueda del bien común de manera organizada en la sociedad, abandonar las guerras y pensar en el bien y el futuro social. La cultura, la conciencia y el humanismo son tres conceptos clave que deben utilizarse en las prácticas cotidianas de las acciones humanas, de allí la importancia que adquiere la disciplina de la historia, como el dispositivo creador e innovador en estas concepciones, con el fin de ser mejores.

El humanismo, ese meta-texto grabado en el tejido social, viene a ser parte de la conformación de la cultura con la que se actúa en la vida cotidiana, que como vínculos simbólicos orientan y dan sentido a la vida individual. Cultura y humanismo son dos términos dinámicos $\mathrm{e}$ intervinientes y para ello el concepto -a la manera de Rüsen, de conciencia histórica- articula temporalmente los tiempos de pasado, presente y futuro de la cultura y del humanismo.

No se soslaya que Reinarth Kosellec en su obra Futuro pasado (citado en Vázquez, 2003) menciona la necesidad de pensar la historia en

10 dos planos: en el espacio de prácticas y el horizonte de expectativas. El primero se conforma por esas acciones sociales del pasado y del presente y el segundo deja abierta la construcción de los futuros deseados. Por ello se menciona que la historia, como parte de sus practicidades, debe ser útil para construir el futuro deseable. No porque tenga la "bola de cristal" para predecir el futuro, sino porque se supone que mediante los imaginarios sociales es posible 
lograrlos; por lo anterior, al ser el futuro pensado en el presente, se convierte en futuro pasado.

Sin el deseo de ser abrumador -y como se mencionó al inicio- esto es solo el atisbo a los conceptos que desde la perspectiva de Rüsen se están trabajando y esperamos que los artículos de este número nos lleven a la reflexión, teniendo presente en nuestra imaginación e idearios la construcción de la conciencia histórica a través de la cultura y el humanismo.

En el primer artículo, denominado La importancia de las Artes en la educación de la nación y el individuo, se encuentran dos visiones para considerar el arte. Una de ellas desde el concepto que se puede rastrear en Ricoeur, la Mímesis, imitación o reproducción de la vida real en imágenes simbólicas artísticas, no del todo aceptada -según el autor- y la segunda desde la visión materialista de la historia, la cual considera el arte como formas específicas de la conciencia social y de las distintas manifestaciones subjetivas que se producen como resultado de las actividades humanas, condicionadas en cada momento histórico. El autor considera que el arte, aparte de ser un contenido educativo, es a la vez un medio para educar a los seres humanos de forma artística, desarrollando la cultura de la educación estética a nivel individual y social; función imprescindible en toda colectividad.

Educación de mujeres: historias de vida en contextos de marginación social, 1930-1970, es la narrativa del espacio de experiencias de la educación de las mujeres de Guanajuato, Guerrero y Oaxaca a mediados del siglo XX, con narrativas focalizadas y direccionadas en la educación, la marginación y el machismo. Como hallazgos que emergieron de las narraciones históricas, se encontró que el sexismo de nuestra sociedad y la construcción ideológica de las mujeres, sigue siendo uno de los principales obstáculos para que ellas realicen estudios formales. 
Historia breve de cuatro asentamientos rarámuri de la ciudad de Chihuahua revisa la cultura de las poblaciones indígenas que migran de la sierra -su lugar de origen- a los centros poblacionales urbanos en busca de mejores condiciones de vida. Estas personas se asienten en las orillas o periferia y en el caso de Chihuahua -único, según expresiones de antropólogos- se ha optado por crear asentamientos humanos con los servicios urbanos y educativos básicos para el desarrollo de su vida y de sus tradiciones culturales. El artículo ofrece una mirada antropológica focalizada en el desarrollo de las prácticas cotidianas que son observables y de los cuestionamientos o preguntas que se les realizan a los moradores de estos cuatro centros o asentamientos raramuri que existen en la ciudad de Chihuahua. El estudio fue realizado en el año 20I7, lo que refleja la actualidad de sus comportamientos, visiones y tensiones.

Los libros de lectura de la escuela primaria como apoyos didácticos en la formación de valores de los niños mexicanos es otro de los artículos, resultado de la investigación comparativa entre los distintos textos que fueron utilizados durante el cardenismo, dos décadas después y el libro de texto actual para el sexto grado de primaria. Se analizan y problematizan los objetivos que pretendían alcanzar con estos materiales en lo que respecta a la formación moral y cívica. Los resultados -a manera de discusión- muestran las semejanzas y diferencias para la formación de lectores, visualizando el horizonte cívico y moral.

Antonio Guízar y Valencia, obispo y arzobispo de Chihuahua, y su influencia en la formación de un laicado católico ajeno a la resistencia armada se toma como un elemento más que explica por qué en el

12 "Estado Grande" -Chihuahua- no hubo participación directa en la En esta entidad no ocurrió lo mismo que en el centro y sur del país, sin soslayar el caso del Padre Maldonado, quien fue masacrado por sus ideas religiosas, pero aquí no se vivió un acontecimiento de armas como el mismo historiador Lorenzo Meyer lo narra, un estado en donde los ex villistas católicos hubieran puesto de cabeza 
al gobierno en un territorio tan diverso y agreste, hubiera contribuido a la causa de los católicos; pero la influencia del obispo Antonio Guizar y Valencia será definitiva en la construcción de una sociedad en la que se prohibía la utilización de las armas para dirimir todo conflicto, lo que conformará un laicado chihuahuense católico combativo pero ajeno a la resistencia armada.

A partir de fuentes documentales de archivo, entrevistas con estudiantes y profesores liberales de la época, e información bibliográfica, se presenta el artículo Política, Reforma Universitaria y sociedad en Puebla (México), I958-1965, que brinda un escenario de la conformación de la sociedad poblana y las visiones que se tenían de la Universidad, institución que será objeto de reformas que llevaron al conflicto en al menos dos proyectos modernizadores y uno de reforma universitaria. El concepto de configuración cultural es central para entender la constitución de los grupos hegemónicos y el subalterno, cómo se fue debilitando uno de los grupos y cómo el otro logra imponer su visión para el desarrollo de la sociedad poblana y la construcción de la Universidad en institución científica y de ascendencia laica.

La construcción de procesos de identidad en las comunidades educativas, el caso del Colegio de Bachilleres del Estado de Chihuahua es un trabajo que se construye a partir de fuentes documentales y de la oralidad de los sujetos entrevistados, quienes proporcionan una panorámica del surgimiento del Colegios de Bachilleres en Chihuahua (COBACH). Se narra el origen de esta institución educativa, debido a la supresión de la Escuela Preparatoria de la Universidad Autónoma de Chihuahua, ya que en los años setentas habían obtenido un grado de concientización y afinidad con las ideas humanistas y democráticas que no eran aceptadas en una sociedad tradicional, por lo que el surgimiento de esta institución viene a llenar el vacío para la conformación del perfil de individuo que se requería en ese momento histórico. Se analizan los conceptos de matrices sociales e individuales en la conformación de la identidad de los estudiantes del Colegios de Bachilleres. 
Finalmente se incluye la Reseña de libro: Miradas históricas a la formación del profesorado en Chihuahua obra que se enfoca en la profesionalización, la vocación de las y los maestros, y los procesos de mejora de las instituciones educativas, puesto que ofrece un diagnóstico de la lógica con la que han operado los profesionales de la educación en diferentes momentos históricos en México. En cada capítulo se ofrecen narrativas históricas, que incluyen expectativas, evoluciones, bienestar y momentos de crisis que impactaron en el tránsito de la formación de las y los docentes, tanto a nivel nacional como -de manera particular- en Chihuahua.

Esperando que la visión plasmada en la editorial y de los artículos que aquí se reseñan, contribuyan -a través de su lectura- a la recuperación de la memoria, a la creación de la cultura y conciencia histórica y se perfilen al humanismo que desde esta disciplina estamos obligados a construir en el futuro próximo. Si se logra esto, habremos tenido el éxito esperado.

Se agradece a los autores y lectores de los artículos sus críticas, comentarios y citas. Les invitamos a seguir construyendo esta comunidad de interesados afines a la disciplina de la historia, mediante el envío de sus ensayos y productos científicos, para darlos a conocer a la sociedad.

\section{Referencias}

Cataño, C. (20II). Jörn Rüsen y la conciencia histórica. Revista historia $y$ sociedad, (2I), 22I-243.

14 Kozlarek, O. (20I7). Jörn Rüsen y el humanismo como luz en tiempos de oscuridad. Intelligere, Revista de Historia Intelectual, 3(2), 34$46 . \quad$ Recuperado de: http://www.revistas.usp.br/revistaintelligere/article/view/1273 03 
Mora, A. (2003). Humanismo y filosofía crítica en Kant. InterSedes: Revista de las Sedes Regionales, V(8). Recuperado de: https://www.redalyc.org/articulo.oa?id=66650813

Sánchez, F. (2009). Cultura histórica. Recuperado de: http://www.culturahistorica.es/sanchez_marcos.castellano.ht $\underline{\mathrm{ml}}$

Santiago, O. (2004). Kant y su proyecto de una paz perpetua (en el bicentenario de su muerte). Revista Digital Universitaria, 5(II), I-II. Recuperado de: http://www.revista.unam.mx/vol.5/numiI/art77/dic art77.pdf

Vázquez, S. (2003). Reseña de "futuro pasado" de Reinhart Koselleck. Relaciones. Estudios de Historia y Sociedad, XXIV (95), 300-305. Recuperado de: https://www.redalyc.org/articulo.oa?id=I37/13709512

Notas

${ }^{I}$ Jörn Rüsen es un historiador y filósofo alemán. Sus investigaciones abordan principalmente los ámbitos de la teoría y la metodología de la historia, la historiografía y la enseñanza de la historia. Nació el I9 de octubre de 1938 y entre varias de sus actividades académico investigativas se menciona el haber sido director del Centro de Investigaciones Interdisciplinares en Bielefeld. Básicamente aquí se rescatan los conceptos de conciencia histórica, cultura y humanismo.

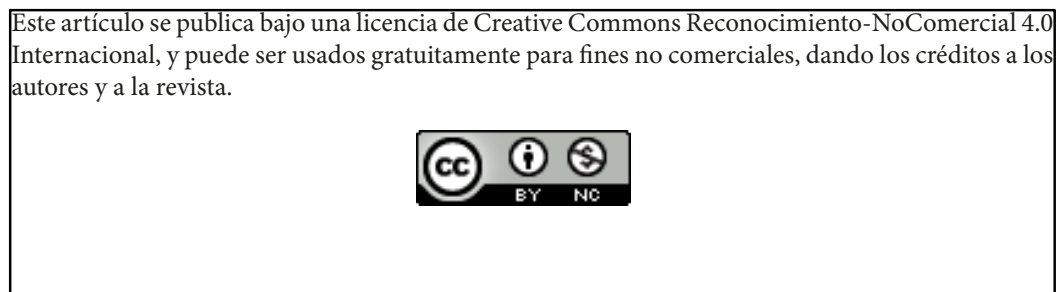

